\title{
Development Trends of Non-thermal Plasma (NTP) Technology Used in Environmental Pollutants Treatment: A Patent-Bibiometric Analysis
}

\author{
Liu Liyuan ${ }^{1,+}$, Gong Yue ${ }^{2,+}$, Chen Yang ${ }^{1, *}$ and Feng Qinzhong ${ }^{1}$ \\ ${ }^{1}$ University of Chinese Academy of Sciences, Beijing 100049, China \\ 2 National Science Library, Chinese Academy of Sciences, Beijing 100190, China \\ ${ }^{\dagger}$ These authors contributed equally
}

\begin{abstract}
Non-thermal plasma Technology (NTP) has been widely used in various fields, especially in environmental pollutants treatment field. This paper provides an overview of the global NTP patent landscape by analyzing relative patents based on CNABS and DWPI, selected from 1987 to 2019, which covers patenting activity related to technologies in pollutant removal from the process in the abovementioned areas. The most common technologies for each area were identified and their developments were analyzed over time. Information related to the main countries, key applicants, current activities and the technology strength were identified by synthesizing important findings from qualitative research and quantitative literature analysis.
\end{abstract}

\section{Introduction}

Non-thermal Plasma (NTP) technology has become a research focus in the field of pollutant control due to its advantages of high efficiency, low energy consumption, co-processing multiple pollutants, and simple operation [1-4]. Currently, NTP has been widely used in various fields, including environmental pollution control, metallurgical refining, etching and material surface treatment, ozone production, etc. ${ }^{[5-7]}$, among which flue gas and wastewater treatment are mostly studied. Its advantages are low energy consumption, low pollutant removal rate, simple reactor structure, wide application range, no secondary pollution, and can achieve coordinated control of pollutants such as $\mathrm{NO}, \mathrm{SO}_{2}$, and $\mathrm{Hg}^{0}$ under normal temperature and pressure ${ }^{[8]}$. Researchers have carried out a lot of research on the application of NTP technology in the treatment of VOCs $^{[9]}$, desulfurization and denitrification ${ }^{[10-14]}$, heavy metal removal ${ }^{[15-18]}$, and also applied for a large number of patents.

Non-thermal Plasma Technology generates highenergy electrons through a high-frequency pulse discharge. The strongest oxidants such as hydroxyl, free radicals and ozone are generated when the high-energy electrons inelastic collision bombard flue gas molecules ${ }^{[1]}$, which will occur complex physicochemical reactions in the discharge field to remove pollutants ${ }^{[4]}$. According to the discharge principle of non-thermal plasma, it can be divided into corona discharge, dielectric barrier discharge, gliding arc discharge, glow discharge and microwave discharge. Only dielectric barrier discharge and corona discharge can produce nonthermal plasma under normal temperature and pressure ${ }^{[2]}$. The patent-bibiometric analysis in a certain technical field can make a preliminary judgment on the technology research trend in this field, and provide trend prediction for future technology trends ${ }^{[19-21]}$.

This study aims to explore the bibliometric overview on NTP technology patents to understand the development trend of the technology in the field of pollution control from 1987 to 2019, and to reveal the technology gaps between China and other countries. Information support can also provide a reference for future patent layout of relevant Chinese institutions in this technical field.

\section{Data sources and search results}

The patents in 2017-2019 related to the NTP technology in Chinese Patent Abstracts (CNABS) and Derwent World Patents Index (DWPI) were collected in April 2020. Based on patent bibliometrics, the NTP treatment technology was classified into two and three levels according to the technical content, application situation or other technical characteristics. 3,328 Chinese patents related to NTP technology and 2,173 foreign patents were obtained (See search strategies in Table 1). Abstracts of these 5501 patents were read one by one, and irrelevant patents were removed. After screening, 1,293 Chinese patents (1,278 after 2000) and 149 foreign patents were retained. In the actual retrieval process, since it is difficult to determine whether it is "nonthermal plasma", in order not to omit data, all documents involving the keyword "plasma" are retained. In the

\footnotetext{
* Corresponding author: chenyang@ucas.ac.cn
} 
manual analysis of data, each patent was indexed and classified as NTP technology according to the technology used. If it can be further distinguished, the NTP technology is further indexed as corona, dielectric barrier or other discharge mode. If it is indistinguishable, it will be indexed as NTP technology with pollutants and discharge mode index "Not clear".

Table 1. Search Strategies

\begin{tabular}{|c|c|}
\hline$\#$ & Search Strategy \\
\hline$\# 1$ & $\begin{array}{l}\mathrm{TS}=(\text { plasma or corona or aureola or aureole or pulse* } \\
\text { or (nanosecond-pulse) or (dielectric and (barrier or } \\
\text { carrier) and discharge*) or DBD) }\end{array}$ \\
\hline$\# 2$ & $\mathrm{IP}=(\mathrm{G} 01 \mathrm{~N} 21 / 73$ or $\mathrm{G} 21 \mathrm{~B} 1 / 23$ or $\mathrm{H} 05 \mathrm{H})$ \\
\hline$\# 3$ & \#1 or \#2 \\
\hline$\# 4$ & $\begin{array}{l}\mathrm{TS}=\left(\left(\left(\text { purify* or recycl* or } \text { remov }^{*}\right) \text { and }(\mathrm{Hg} \text { or }\right.\right. \\
\text { mercury or mercur* })) \text { or demercur* })\end{array}$ \\
\hline$\# 5$ & $\begin{array}{l}\mathrm{TS}=(((\text { purify* or recycl* or remov*) and (SOx or SO2 } \\
\text { or SO3 or ((sulfur or sulphur) and oxide }))) \text { or } \\
\text { desulfur*) }\end{array}$ \\
\hline \#6 & $\begin{array}{l}\mathrm{TS}=\left(\left(\left(\text { purify* or recycl* or } \text { remov*}^{*}\right) \text { and }(\mathrm{NOx} \text { or }\right.\right. \\
\mathrm{NO} 2 \text { or (nitrogen and oxide }))) \text { or denitr*) }\end{array}$ \\
\hline$\# 7$ & $\begin{array}{l}\text { TS }=((\text { purify* or recycl* or remov*) and (dioxin or } \\
\text { PCDD or PCDF or chlorobenz }))\end{array}$ \\
\hline$\# 8$ & $\begin{array}{l}\mathrm{TS}=\left(\left(\text { purify* or recycl* or remov*) and }\left(\mathrm{VOC}^{*} \text { or }\right.\right.\right. \\
\text { tvoc or }(\text { volatile or organic or compound } *)))\end{array}$ \\
\hline$\# 9$ & $\# 3$ and \#4 \\
\hline$\# 10$ & $\# 3$ and $\# 5$ \\
\hline$\# 11$ & $\# 3$ and \#6 \\
\hline$\# 12$ & $\# 3$ and \#7 \\
\hline$\# 13$ & $\# 3$ and $\# 8$ \\
\hline$\# 14$ & $\# 9$ or $\# 10$ or $\# 11$ or $\# 12$ or $\# 13$ \\
\hline \#15 & $\# 14 \operatorname{not} P N=C N$ \\
\hline
\end{tabular}

\section{Results}

\subsection{Development of NTP technology in related patents}

NTP technology has undergone a major transformation from space plasma exploration in the early 1960s to materials-oriented research in the 1980s and 1990s. With the rapid development of microelectronics science, environmental science, energy and material science, and physical technology, etc, has brought new opportunities to NTP technology. Since the 1980s and 1990s, global researchers began to use discharge plasma to oxidize $\mathrm{Hg} 0$. In recent decades, research on plasma technology has been very active, providing a new technology, new method and a new process for the synthesis of new substances, new materials and environmental pollution control.NTP technology degradation of pollutants is to use these high-energy electrons, free radicals and other active particles and pollutants in the exhaust gas to decompose pollutant molecules in a very short time, and various subsequent reactions occur to achieve the degradation of pollutants. The development trend of related patents from 1987 to 2019 is shown in Figure 1.

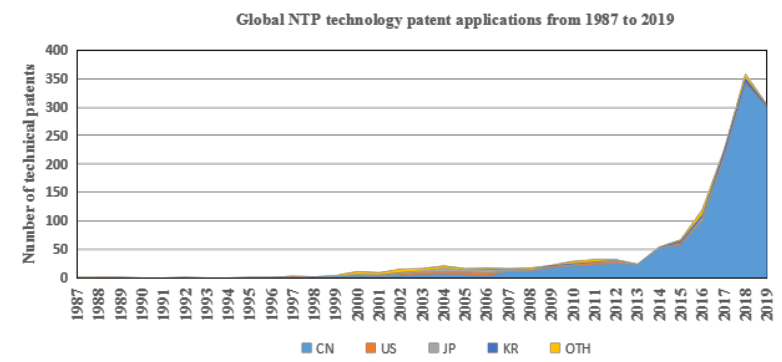

Fig. 1. Chronological patenting activities of Non-thermal plasma Technology (NTP)

\subsection{Geographical patent priority distribution of major countries/regions}

Regional distribution showed that there are slight differences in the number of patent applications in different countries/regions. The United States started at the earliest in 1988, and then applicated intermittently in 1989 and 1997, and increased its applications largely from 2003 to 2006, and continued at 5 applications in the subsequent years. The development of patenting activities in China and Japan lags latter that of the United States. Japan started in 1997, about 10 years later than the United States, and reached a relatively high annual number of applications between 2004 and 2008, which was approximately 5, and then showed a downward trend. China has applied for NTP technology since 1992, and increased the number of applications yearly. In the period of 2007-2013, the number of applications in China reached a peak for the first time, with 20 applications annually, and then increased to 50-100 annually after 2014, which occupied an important position in the patenting activities of NTP technology in the world (See Fig.1).

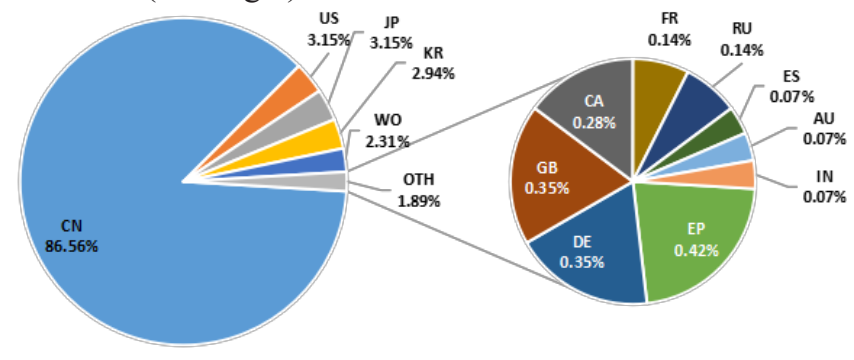

Fig. 2. Proportion of the main priority countries or regions with the earliest priority for patents related to NPT (2000-2019) 
As shown in Fig. 2, China ranked No.1 with 1,237 applications after 2000, and the number of applications has increased significantly (from $73.9 \%$ to $86.56 \%$ ) since 2017. The United States and Japan followed closely, accounting for $3.15 \%$, and South Korea ranked No.4 with $2.94 \%$. It can be seen that the patent applications of China, the United States, Japan, and South Korea account for nearly $90 \%$ of the total NTP technology applications. And the large number of patent applications in China is mainly due to its much more attention to NTP technology patenting activities in environmental protection and pollution control.

\subsection{Thematic analysis on NTP technology}

\subsubsection{Thematic analysis on NTP technology patents on target pollutants}

The NTP technology patent applications for different target pollutants from 2000 to 2019 are shown in Fig. 3.

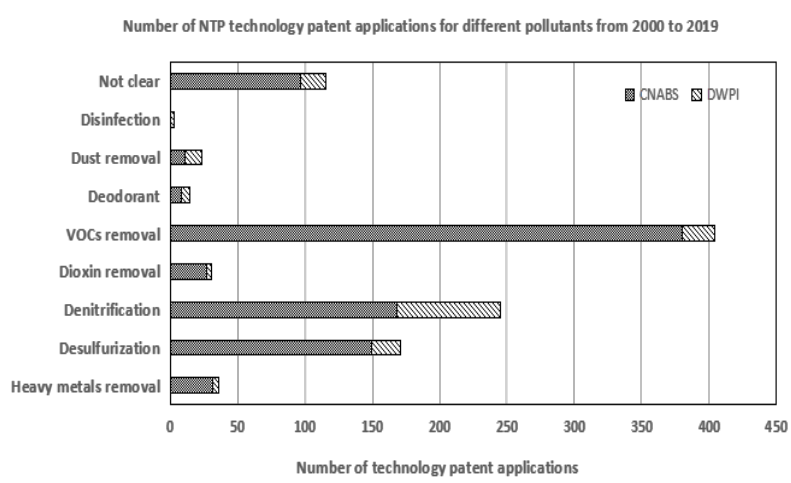

Fig. 3. Patent applications of NPT for different pollutants from 2000 to 2019

It can be seen that the NTP technology from 2000 to 2019 is mainly used for the removal of conventional pollutants such as denitrification, desulfurization, and removal of VOCs, which was affected by the general requirements of the air pollutant emission industry for these pollutants. In recent years, with the gradual tightening of national pollution emission standards, the application and patent applications of NTP in removing mercury, dioxins and other unconventional pollutants have gradually increased.

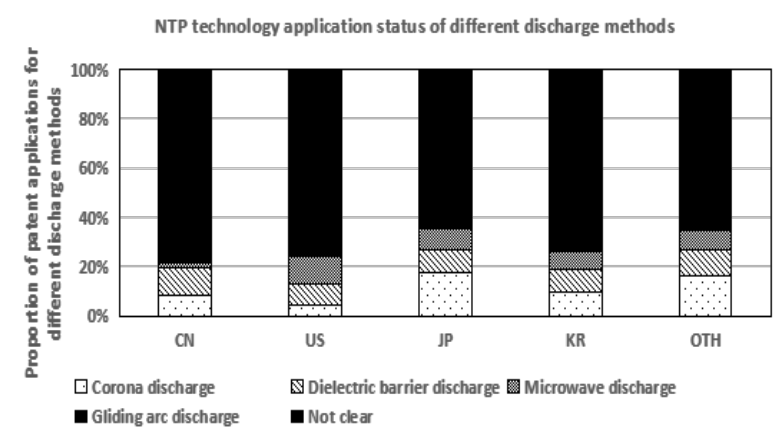

Fig.4 NTP patent applications for different pollutants in major countries from 2000 to 2019
As showed in Fig. 4, China' s NTP technology patent applications mainly focused on VOCs removal, the denitration and desulfurization, which accounted for $25.3 \%$ and $15.2 \%$ of the total respectively. Dust removal, deodorization, mercury removal, dioxin removal, disinfection and sterilization technologies accounted for $6.2 \%, 6.1 \%, 3.1 \%, 2.8 \%$, and $2.3 \%$ respectively. The US patent applications for NTP technology mainly focused on denitration technically, which accounted for $51.0 \%$ of the total, followed by desulfurization and VOC removal technologies $(13.0 \%$ and 16.3\%). Japan's NTP technology patent applications mainly focused on denitration technology, accounting for $40.0 \%$ of the total, which was followed by desulfurization $(10.0 \%)$ and VOCs removal technologies(6.0\%). South Korea's NTP technology patent applications mainly focused on denitration technology, accounting for $30.6 \%$ of the total, followed by VOCs removal (20.4\%) and dust removal technology (12.2\%). It can be seen that China focused on desulfurization, denitrification and VOCs removal technologies, with a balanced development of these three technologies, while other countries paid more attention on denitration obviously.

\subsubsection{Thematic analysis on NTP technology patents on discharge mode}

Fig. 5 shows the patent applications of NTP technology for different discharge methods from 2000 to 2019.

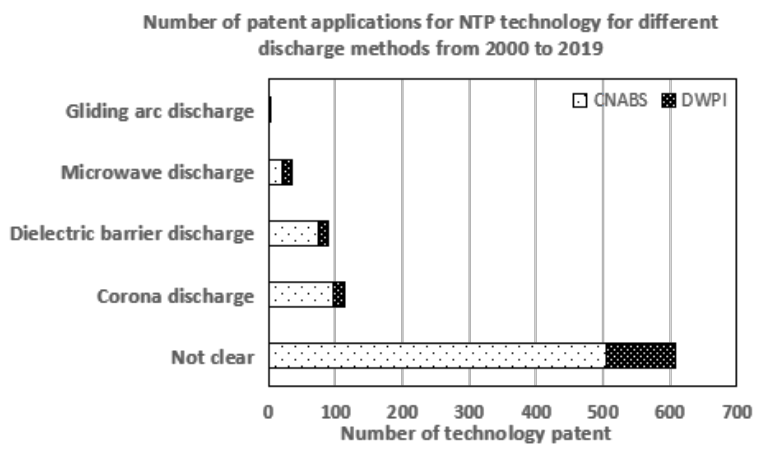

Fig.5. Patent applications of NPT for different discharge methods from 2000 to 2019

In 213 NTP technology patents from 2000 to 2019, there are mainly four discharge methods: corona discharge, dielectric barrier discharge, microwave discharge and gliding arc discharge. And according to the number of patents, corona discharge is a relatively mature NTP technology (13.41\%).

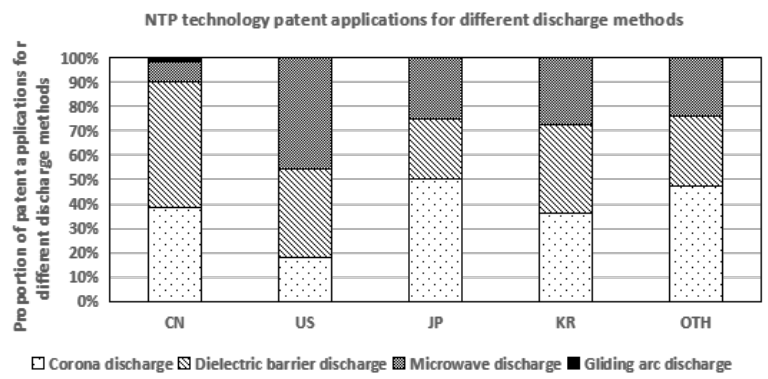


Fig.6. NTP patent applications for different discharge methods from 2000 to 2019

As shown in Fig. 6, dielectric barrier discharge accounted for the main part of the patents in each country. China has applied for more patents on dielectric barrier discharge (11.2\%) and corona discharge (8.5\%). And microwave discharge and dielectric barrier discharge, which were used more frequently in the United States, accounting for $11.1 \%$ and $8.9 \%$ in the number of related patents, respectively. The technology adopted in Japan was mainly corona discharge technology, accounting for $17.8 \%$, and dielectric barrier discharge and microwave discharge (8.9\%). Among these technologies, South Korea, applications for corona discharge and dielectric barrier discharge technology is equivalent, each accounting for $9.5 \%$. In general, the different technology preference between China, South Korea (corona discharge technology) and the United States (microwave discharge technology) may be related to the positioning of different pollutant removal targets of the patented technology.

\subsubsection{Global patent applicants on NTP technology}

There were about 400 applicants of NTP technology in the world, and approximately $15 \%$ of the number of patents were held in the top 15 applicants, such as Zhejiang University, Huang Liwei, Dalian Maritime University, Jiangsu University, Southeast University, Tokyo Perseverance Technology Co., Ltd., etc. Among the top 15 applicants, 12 were from China, which inferred that Chinese universities and research institutes are at the forefront of NTP technology research and development. (See Table 2)

Table 2. Number of patent applications from TOP15 applicants

\begin{tabular}{|c|c|c|}
\hline No. & Applicant & $\begin{array}{c}\text { Number of patent } \\
\text { applications }\end{array}$ \\
\hline 1 & Zhejiang University & 11 \\
\hline 2 & Huang Liwei & 10 \\
\hline 3 & $\begin{array}{c}\text { Dalian Maritime } \\
\text { University }\end{array}$ & 8 \\
\hline 4 & $\begin{array}{c}\text { Jiangsu University } \\
\text { Southeast University }\end{array}$ \\
\hline 6 & $\begin{array}{c}\text { Tokyo Perseverance } \\
\text { Technology Co., Ltd. }\end{array}$ & 6 \\
\hline 7 & $\begin{array}{c}\text { Beijing University of } \\
\text { Aeronautics and } \\
\text { Astronautics }\end{array}$ & 5 \\
\hline 8 & $\begin{array}{c}\text { Dalian University of } \\
\text { Technology }\end{array}$ & 5 \\
\hline
\end{tabular}

\begin{tabular}{|c|c|c|}
\hline No. & Applicant & $\begin{array}{c}\text { Number of patent } \\
\text { applications }\end{array}$ \\
\hline 9 & $\begin{array}{c}\text { Guangdong Jiade } \\
\text { Environmental } \\
\text { Technology Co., Ltd. }\end{array}$ & 5 \\
\hline 10 & $\begin{array}{c}\text { North China Electric } \\
\text { Power University }\end{array}$ & 5 \\
\hline 11 & $\begin{array}{c}\text { Shandong Pailidi } \\
\text { Environmental } \\
\text { Engineering Co., Ltd. }\end{array}$ & 4 \\
\hline 12 & $\begin{array}{c}\text { Toyota Motor Corporation } \\
\text { Fudan University }\end{array}$ & 4 \\
\hline 13 & Nanjing University & 4 \\
\hline 15 & Honda & 4 \\
\hline
\end{tabular}

\section{Conclusions and prospects}

As the control of environmental pollution has been paid more and more attention, NTP technology is developing rapidly in recent years. And the number of Chinese patent applications has increased more quickly than the global applications, due to its increasing investment and development of NTP technology, which also shows that Chinese market's large demand for NTP technology, as well as the enterprises and R\&D institutions' attention to the value of NTP technology. From a global perspective, the number of NTP patent applications in China currently ranks first, and countries and regions such as the United States, Japan, Europe and South Korea still maintain a strong momentum in NTP technology patent applications. Although these countries and regions have a lower proportion of patent applications than China, due to their large number of technical research and development personnel and strong technical strength, the development trend in subsequent NTP technology research and development and patent applications still cannot be ignored. Moreover, in order to continue to enhance core competitiveness in this field in the future, it is necessary to continue to increase investment in research and development of NTP technology on the basis of maintaining a rapid increase in the number of applications. In addition, as NTP technology has a wide range of applicability, major applicants also need to pay attention to the main research areas of advanced companies, establish their own research and development directions in the field, learn to write highquality patent application documents, and formulate corresponding intellectual property strategies.

\section{Acknowledgments}

This work was financially supported by the Beijing Municipal Sciences \& Technology Commission 
(Z181100003818009), National Key Technologies R\&D Program of China (No.2016YFC0209200) and Youth Innovation Promotion Association, CAS (2016151).

\section{References}

1. Fan Yanxiang, Chen Yang, Yin Lianqing. Research of the NTPoxidation effect on $\mathrm{Hg}^{0}$. Environmental Engineering, 35(3): 82-86,136. (2017)

2. Zhu Tao. Research of NTP technology on VOCs removal[M]. Beijing: Metallurgical Industry Press, 9.10.(2005)

3. Areyiguli. Numerical simulation study of NTP on mercury flue gas. Institute of High Energy Physics, Chinese Academy of Sciences, (2014)

4. Yu Zhengxian. Application of plasma technology in air pollution control. Guangdong Chemical Industry, 3(7): 131.(2009)

5. Chen Dianying. NTP and its application in exhaust gas treatment . Chemical Environmental Protection, 21(3): 136.139. (2001)

6. Li Jie, Li Jian, Jin Yukui, etc. NTP technology to treat volatile organic compounds. Environmental Pollution Control Technology and Equipment, 7(6): 101-105. (2006)

7. Sun Wei, Yan Naiqiang, Jia Jinping. Study on the removal of elemental mercury by activated carbon loaded with sulfur and chlorine compounds. Environmental Science and Technology, 29(12): 8486. (2006)

8. Wu Chengkang. Physics, 2(87): 388-393. (1999).

9. Lu SY, Sun XM, Li XD, et al. Decomposition of Toluene in a Rotating Glidarc Discharge Reactor. IEEE Transactions on Plasma Science, 40(9): 21512156. (2012)

10. Durme JV, Dewulf J, Sysmans W. Efficient toluene abatement in indoor air by a plasma catalytic hybrid system. Applied Catalysis B: Environmental, 74(12): 161 - 169. (2007)

11. Mok YS, Nam IS,. Positive pulsed corona discharge process for simultaneous removal of $\mathrm{SO}_{2}$ and $\mathrm{NO}_{\mathrm{x}}$ from iron-ore sintering flue gas. IEEE Transactions on Plasma Science, 27:1188-1196. (1999)

12. Obradović BM, Sretenović GB, Kuraica MM. A dual-use of DBD plasma for simultaneous NOx and $\mathrm{SO}_{2}$ removal from coal-combustion flue gas. Journal of Hazardous Materials, 185(2-3):1280-1286. (2011)

13. Wang Ninghui, Yue Zhibin, Cui Yuefeng. Pulse discharge flue gas dust removal and $\mathrm{NO}_{2}$ and $\mathrm{NOx}$ removal research. China Environmental Science, 17(3):212-215. (1997)

14. Wang MY, Zhu TL, Wang H. Oxidation and removal of NO from flue gas by DC corona discharge combined with alkaline absorption[J]. 39(2):704-710. (2011)

15. Bai $\mathrm{MD}, \mathrm{Hu}$ J. Oxidization of $\mathrm{SO}_{2}$ by reactive oxygen species for flue gas desulfurization and
$\mathrm{H}_{2} \mathrm{SO}_{4}$ production[J]. Plasma Chem Plasma Process, 32: 141-152. (2012)

16. Meiyan Wang, Tianle Zhu, Hongjing Luo, et al. Effects of reaction conditions on elemental mercury oxidation in simulated flue Gas by DC Non-thermal Plasma. American Chemical Society, 50: 5914-5919. (2011)

17. Hao Shuoshuo, Research of NTP treatment on mercury flue gas. North China Electric Power University. (2016)

18. Gong Yue, Liu Liyuan, Chen Yang. Trend analysis of mercury pollution control technology based on patent measurement. Journal of Environmental Engineering, 6: 1473-1486.(2019)

19. Yang Yuhan; Jin Wei; Liu Liyuan, et al. Bibliometric analysis of mercury pollution prevention and control based on SCI papers. Journal of Environmental Engineering, 6: 1487-1501. (2019)

20. Zheng Xiaomei; Gu Xinsheng; Qu Na, et al. Bibliometric analysis of mercury pollution prevention and control technology based on Chinese journal articles. Journal of Environmental Engineering, 6: 1502-1512. (2019) 